\title{
LODO DE ESGOTO COMO FERTILIZANTE: PRODUTIVIDADE AGRÍCOLA E RENTABILIDADE ECONÔMICA
}

\author{
QUINTANA, Núria Rosa Gagliardi ${ }^{1}$ \\ CARMO, Maristela Simões do ${ }^{2}$ \\ MELO, Wanderley José de ${ }^{3}$
}

\begin{abstract}
RESUMO: O objetivo dessa revisão é analisar a disposição agrícola do lodo de esgoto como potencial biofertilizante, do ponto de vista produtivo e econômico em detrimento de sua deposição em aterros sanitários. $\mathrm{O}$ lodo de esgoto é considerado um excelente biofertilizante devido à quantidade de matéria orgânica e macro e micronutrientes nele contidos, contribuindo assim, com a diminuição do uso de fertilizantes industriais e redução nos custos de adubação. Sua reciclagem agrícola deve obedecer às regras que definem as exigências de qualidade do material, limitações ambientais e edáficas, taxa de aplicação e cultura agrícola recomendada. Os aterros sanitários garantem o destino correto deste resíduo quando inadequado para os demais usos ou excedentes à demanda. Para que esse resíduo venha a ser considerado matéria-prima, são necessários estudos que confirmem a segurança de seu uso ao meio ambiente e à saúde humana.
\end{abstract}

Palavras-chave: Reciclagem agrícola. Adubo orgânico. Bens substitutos.

\section{SEWAGE SLUDGE AS FERTILIZER: AGRICULTURAL PRODUCTIVITY AND ECONOMIC RENTABILITY}

SUMMARY: The purpose of this review is analyzing provision of agricultural sewage sludge as a biofertilizer in terms economic and productive rather than being deposited in landfills. Sewage sludge is considered an excellent biofertilizers because of organic matter amount and macro and micronutrients contained in them, thus contributing to the decreased industrial fertilizers use and reduction in fertilization costs. Its agricultural recycling must obey the quality rules of this material, soil type, environmental constraints, application rate and crop recommended. Landfills ensure the correct destination when this waste unsuitable for other uses or excess demand. For this residue become considered raw material, studies are needed that confirm the safety of its use to the environment and human health.

Keywords: Agriculture recycling. Organic fertilizer. Substitute goods.

\section{INTRODUÇÃO}

Com a crescente pressão da sociedade pela despoluição dos mananciais, e a possível escassez de água que compromete algumas regiões do país, é necessário e oportuno que o tratamento de esgotos venha a tornar-se rotineiro. Contudo, parte da população não conta sequer com os serviços básicos de saneamento.

\footnotetext{
${ }^{1}$ Engenheira Florestal, Doutora em Energia a Agricultura pela Faculdade de Ciências Agronômicas (FCA), Universidade Estadual Paulista (UNESP).

${ }^{2}$ Engenheira Agrônoma, Professora Adjunta do Departamento de Gestão e Tecnologia Agroindustrial, Faculdade de Ciências Agronômicas (FCA) da Universidade Estadual Paulista (UNESP) e Professora Colaboradora da Pós-Graduação da FEAGRI/UNICAMP.
} 
As Estações de Tratamento de Esgotos (ETEs), ao submeterem este material a processos que possibilitem o retorno da água no ambiente, geram resíduo denominado lodo de esgoto, conhecido também por biossólido, e conseqüentemente, outro problema que é a destinação deste resíduo.

Entre as opções disponíveis como a incineração, deposição oceânica e florestal, a utilização agrícola como fertilizante tem sido considerada promissora.

A utilização como biofertilizante, substituindo os fertilizantes industriais, evita gastos econômicos e energéticos próprios da atividade de fertilização do solo. Se depositado em aterros sanitários, com altos custos de manutenção, perde-se a energia que poderia ser empregada adequadamente de outras formas, além de proporcionar risco de contaminação de solos e lençóis freáticos, o que gera gastos na sua manutenção.

Os elevados teores de matéria orgânica, além dos macro e micronutrientes existentes no lodo de esgoto, permitem-no ser comparado a um biofertilizante potencial, capaz de proporcionar outros efeitos benéficos ao solo que não acontecem com a adição dos adubos químicos.

O lodo de esgoto é rico também em microorganismos e nutrientes tais como nitrogênio e fósforo, essenciais para o desenvolvimento das plantas e obtenção de boa produtividade. Este material passa por diversos tratamentos e controles de qualidade, que garantem a sua higienização e eficácia para ser utilizado como fertilizante. (QUINTANA, 2006).

Segundo Malta (2001), o lodo de esgoto altera as propriedades físicas do solo, melhorando sua densidade, porosidade e capacidade de retenção de água. Além disso, melhora seu nível de fertilidade, elevando o $\mathrm{pH}$, diminuindo o teor de alumínio trocável, aumentando a capacidade de troca de cátions (CTC) e a capacidade de fornecer nutrientes para as plantas; e ainda, por conter em sua constituição teores elevados de matéria orgânica e de outros nutrientes, promove o crescimento de organismos do solo, os quais são de fundamental importância para a ciclagem dos elementos.

As ETEs da grande São Paulo, produzem por dia, 2000 t de lodo de esgoto, o que contém, em média, 20 t de $\mathrm{N}, 50$ t de $\mathrm{P}_{2} \mathrm{O}_{5}, 6$ t de $\mathrm{K}_{2} \mathrm{O}$ e 120 t de matéria orgânica. $\mathrm{O}$ gasto de energia para produzir o fertilizante correspondente é equivalente a cem mil barris de petróleo por ano. (GOBBI, 2003).

Entretanto, a origem do lodo de esgoto deve ser considerada quanto à possibilidade de seu uso na agricultura, uma vez que as quantidades de metais pesados e agentes patogênicos podem limitar o seu emprego. Vários estudos buscam definir a quantidade ideal de lodo de

\footnotetext{
${ }^{3}$ Engenheiro Agrônomo, Professor Titular do Departamento de Tecnologia, Faculdade de Ciências Agrárias e Veterinárias (FCAV) da Universidade Estadual Paulista (UNESP).

Nucleus, v.8, n.1, abr.2011
} 
esgoto a ser aplicado nas diferentes culturas. Algumas restrições estão relacionadas, principalmente, ao seu emprego na horticultura.

Bettiol; Camargo (2000), afirmam que, seguindo em busca de satisfazer essas necessidades, o lodo de esgoto é empregado como recurso alternativo com êxito, não só na atividade agrícola, mas também na atividade florestal; reuso industrial (produção de agregado leve, fabricação de tijolos e cerâmica e produção de cimento); conversão em óleo combustível e recuperação de solos.

Ainda que haja alguns riscos, é possível reconhecer diversos benefícios originários da aplicação do lodo de esgoto, tais como, redução de custos, conservação do ambiente e das características físicas e químicas do solo.

\section{USO AGRÍCOLA DO LODO DE ESGOTO}

O lodo de esgoto pode ser usado como fertilizante granulado complexo quando reunido no mesmo grânulo juntamente com sais minerais; como mistura de fertilizantes minerais e orgânicos em grânulos ou em pó e, como carga numa formulação mineral substituindo carga inerte para atingir o peso padrão comercial de uma tonelada. (TSUTIYA, 2001). O mesmo autor afirma que, por aproveitarem melhor a composição química do lodo de esgoto e desprezarem os riscos de contaminação com patógenos, algumas culturas são mais indicadas para receberem fertilização com este tipo de material. É o caso do milho e das gramíneas, além de atividades como reflorestamento, recuperação de áreas degradadas e fruticultura.

Frank (1998), afirmou que o emprego de lodo de esgoto como fertilizante reduziria $60 \%$ do consumo de fertilizantes fosfatados utilizados, indo ao encontro da afirmação de Tsutiya (2000) de que na grande São Paulo a produção diária de lodo de esgoto atinge algo em torno de 2,4 toneladas de fósforo. Este biofertilizante, além de fósforo, oferece também nitrogênio e outros nutrientes para as plantas, contribuindo com o seu desenvolvimento. (SABBEY, 1974).

No entanto, é preciso cuidado porque o uso exclusivo de lodo de esgoto como fertilizante pode causar deficiências nutricionais para as culturas devido ao desequilíbrio no teor de nutrientes oferecidos. (SOUZA, 2004).

De fato, avaliando a viabilidade da utilização de substratos compostos pela mistura de diferentes proporções de lodo de esgotos com casca de arroz carbonizada, Trigueiro (2002) estabeleceu ensaio para produção de mudas de eucalipto e pinus, em proporções variando de 0 a $100 \%$ entre lodo de esgotos e casca de arroz carbonizada. Os resultados revelaram que doses 
superiores a $70 \%$ de lodo de esgoto foram prejudiciais ao desenvolvimento das mudas de ambas as espécies.

Por isso, Trannin (2004) explica que a variabilidade da composição química e do teor de umidade do lodo de esgoto dificulta a busca por padrões das doses recomendadas, exigindo estudos que permitam uma utilização agronômica segura.

Várias pesquisas concluíram que o lodo de esgoto levou ao desenvolvimento e produtividade maior ou igual ao proporcionado pelos fertilizantes convencionais. Andreoli \& Pegorini (2000), por exemplo, afirmam que este é o caso dos cereais.

Ao avaliar a eficiência do lodo de esgoto como fonte de fósforo em comparação ao superfosfato triplo, aplicados em doses equivalentes, Silva et al., (2002a) notaram que aquele foi mais eficiente do que este.

Galdos, et al. (2004) realizaram experimento com duração de dois anos agrícolas, para determinar as alterações que a aplicação de lodo de esgoto gerou sobre os teores de fósforo, entre outros elementos, num Latossolo Vermelho eutroférrico cultivado com milho. Observaram que a produção foi maior nos tratamentos com este tipo de fertilização, onde os teores de fósforo no solo foram semelhantes aos do tratamento com adubo químico.

Nascimento et al. (2004), ao estudarem o efeito da aplicação de doses crescentes de lodo de esgoto gerado pela Companhia Pernambucana de Saneamento (COMPESA) sobre o crescimento das plantas de milho e feijão cultivadas em casa de vegetação, concluíram que doses crescentes aumentaram a produção de matéria seca em ambas.

Quintana et al. (2004) afirmaram que a substituição da fertilização nitrogenada inorgânica por lodo de esgotos proporcionou melhoria de alguns parâmetros da couve brócolos de cabeça única (Brassica oleraceae var. italica, híbrido decathlon), tais como número de folhas comercializáveis, diâmetro médio de caule e de cabeça e peso médio de cabeça.

Rocha et al. (2004) avaliaram o estado nutricional e o crescimento de um povoamento de Eucalyptus grandis fertilizado com lodo de esgoto. Na ocasião, notaram que a aplicação deste resíduo influiu positivamente na nutrição das plantas, proporcionando produção de madeira igual à obtida no tratamento que só recebeu adubação mineral, quando a dose aplicada de lodo de esgoto foi de $12 \mathrm{t} \mathrm{ha}^{-1}$.

Trannin (2004); por sua vez, observou que o lodo de esgoto melhorou a fertilidade do solo, o estado nutricional e a produtividade do milho.

De acordo com Almeida et al. (2005), o incremento da biomassa aérea e radicular de espécies arbóreas aumentou perante doses crescentes de lodo de esgoto aplicadas no plantio. 
A utilização de lodo de esgoto como biofertilizante e condicionador de solos, permite ganhos ao produtor, através do aumento da produtividade das culturas e redução do uso de fertilizantes minerais, com ganhos para os geradores de lodo, pela efetivação de métodos adequados e mais econômicos de disposição final desse resíduo. (GUEDES et al., 2006).

No entanto, Tsutiya (2001) observa que, para que possam receber aplicação de lodo de esgotos, as áreas cultiváveis devem obedecer à legislação vigente, especialmente a Florestal, proporcionar facilidade de acesso durante a deposição do material, e respeitar outras limitações, como a proximidade de áreas residenciais, a direção predominante de ventos e a declividade mínima.

\section{DEPOSIÇÃO DO LODO DE ESGOTO EM ATERRO EXCLUSIVO}

Com o objetivo de absorver os lodos de esgotos inadequados para os mais diversos usos ou excedentes à demanda, o aterro sanitário busca garantir o destino correto deste resíduo. Um aterro mal projetado pode provocar a contaminação do ar, de águas superficiais e subterrâneas, do solo e, conseqüentemente, da população.

Além disso, os aterros sanitários já são responsáveis por um terço das emissões de metano que contribuem para as mudanças climáticas. Por isso, entre os principais objetivos da Lei de Enquadramento Européia sobre aterros sanitários estão a redução da quantidade de lixo biodegradável despejado nos aterros (a maior fonte do metano) e a promoção de instalações de coleta de metano para seu uso na produção de energia. (ATERRO, 2010).

Para contornar estes problemas, Tsutiya (2001) afirma que é necessário que o aterro tenha localização adequada, elaboração de projeto criterioso, implantação de infra-estrutura de apoio, elementos de proteção ambiental e gerenciamento. O mesmo autor explica que, no aterro exclusivo, os lodo de esgotos são depositados após serem secos termicamente ou como tortas tratadas. Ensaios geotérmicos mostram que tortas com $40 \%$ de lodo de esgotos com cal virgem, ou 90\% de sólidos, são as mais adequadas para este tipo de destino.

A solução, embora boa, não é a melhor do ponto de vista econômico. Para construir um aterro sanitário convencional é necessário elaborar um EIA/RIMA (Estudo de Impacto Ambiental/Relatório de Impacto no Meio Ambiente), que custa aproximadamente R\$ 100 mil. Numa solução dita "convencional", entre o projeto e a construção de aterro sanitário com manta e tratamento do chorume, o custo está em torno de R $\$ 1,2$ milhão, preço médio dos aterros implantados pela Conder (Companhia de Desenvolvimento Urbano do Estado da Bahia), por exemplo. (CONDER, 2010). 
Caso a empresa geradora opte por depositar seus resíduos em aterros particulares, é de responsabilidade do gerador o transporte dos resíduos até o aterro, ou seja, a empresa deve contratar o caminhão adequado para o transporte.

De qualquer forma, compostagem, coleta seletiva e reciclagem são fatores importantes para aumentar a vida útil dos aterros, desde que haja demanda e mercado para os produtos ou materiais obtidos com a utilização desses processos.

\section{PRODUTIVIDADE E RENTABILIDADE DO LODO DE ESGOTO COMO FERTILIZANTE}

A utilização agrícola de lodo de esgoto destaca-se por evitar destinos de custos mais elevados e com maior impacto no ambiente e na população, como por exemplo, a disposição em aterros sanitários. (ANDREOLI et al., 1999).

Por outro lado, a disposição agrícola do lodo de esgoto é vantajosa aos agricultores, na medida em que reduz os custos de produção e mantém a produtividade da lavoura. (TRANNIN et al., 2005).

Raij (1998) defende que os benefícios da aplicação do lodo de esgoto podem superar os da adubação mineral, principalmente em relação à economia com fertilizantes.

Trigueiro (2002) produziu mudas de eucalipto e pinus com excelentes resultados. No caso da primeira espécie, houve redução nos custos com fertilizantes de 64\%, e de 12,5\% para a segunda espécie, quando as mudas foram produzidas com lodo de esgoto.

Silva et al. (2002b), ao estudarem a relação benefício/custo da aplicação de biossólido na produção de milho, concluíram que embora a produção física tenha aumentado com o acréscimo da dose de 54 até $216 \mathrm{t} \mathrm{ha}^{-1}$, a análise da relação benefício/custo mostrou que doses muito elevadas podem não ser economicamente vantajosas.

Da mesma forma, Gobbi (2003), analisando a potencialidade do lodo de esgoto como fonte de macronutrientes no cultivo do milho, constatou que a utilização deste material proporcionou maior receita bruta do que o tratamento com adubação química. No entanto, o mesmo autor inferiu que, embora a maior dose de lodo de esgoto tenha alcançado a maior produção física, produziu a menor renda líquida.

Em outro estudo, Quintana et al. (2009) concluíram que dentro das doses de lodo de esgoto aplicadas $\left(5\right.$ t.ha ${ }^{-1}, 10$ t.ha $^{-1}$ e 20 t.ha $\left.^{-1}\right)$ no milho de verão cultivado em Latossolo Vermelho distrófico e Latossolo Vermelho eutroférrico, a dose economicamente adequada, calculada através de análise de regressão, foi de 13,50 toneladas (base seca) por hectare nos dois tipos de solo, tanto para a rentabilidade efetiva como para a total. 
Isso é explicado por Hoffman et al. (1987) através da função de produção; relação que expressa a quantidade máxima de produto obtido através de um conjunto de insumos, dada a tecnologia disponível, por unidade de tempo. Os autores esclarecem que à medida que se aumenta a quantidade empregada de um fator variável, mantendo-se os demais constantes, o produto físico total aumenta a princípio mais do que proporcionalmente à quantidade empregada, depois menos que proporcionalmente, atinge um máximo e, finalmente, decresce.

No entanto, por se tratar de um produto de recente utilização na agricultura, seu uso gera dúvidas quanto ao custo do produto em relação aos fertilizantes convencionais e requer um estudo mais completo na avaliação econômica de sua aplicação. (SILVA et al., 2002b).

Ao estudar a produtividade do milho cultivado em latossolos fertilizados com lodo de esgoto, Melo (2002) concluiu que este biofertilizante pode ser utilizado em substituição parcial ao fertilizante mineral, sugerindo que seu uso diminuiria os elevados custos da fertilização.

\section{CONSIDERAÇÕES FINAIS}

O lodo de esgoto é um subproduto do tratamento de águas residuárias que contém alguns dos macro e micronutrientes necessários às plantas, é rico em matéria orgânica e por isso pode melhorar produtividade das culturas. Com isso, esse material pode vir a ser um complemento capaz de reduzir a utilização de fertilizantes industriais e diminuir os custos de adubação. Cabe ressaltar também que a incorporação de lodo nos solos é o manejo economicamente mais vantajoso, quando comparado a demais alternativas de disposição.

Contudo, sua reciclagem agrícola deve obedecer às regras que definem as exigências de qualidade do material, além de outros aspectos, tais como: limitações ambientais e edáficas, taxa de aplicação e cultura agrícola recomendada.

Apesar do potencial do lodo de esgoto como biofertilizante, sua disposição final é responsabilidade da unidade geradora.

Estudos são necessários para que se confirme a segurança do uso do lodo de esgoto ao meio ambiente e à saúde humana e esse resíduo venha a ser considerado matéria-prima.

\section{REFERÊNCIAS}

ALMEIDA, G. J. F.et al. Efeito do biossólido aplicado no plantio no desenvolvimento aéreo e radicular de espécies arbóreas In: SIICUSP, 13, 2005, Piracicaba. Anais... Esalq/USP, 2005. CD-Rom. 
ANDREOLI, C. V.; LARA, A. I.; FERNANDES, F. Reciclagem de biossólidos: transformando problemas em soluções. Curitiba: Sanepar; Finep, 1999. 288p.

ANDREOLI, C. V. ; PEGORINI, E. S. Gestão pública do uso agrícola do lodo de esgoto. In: BETTIOL, W.; CAMARGO, O. A. (Ed.). Impacto ambiental do uso agrícola do lodo de esgoto. Jaguariúna: Embrapa Meio Ambiente, 2000. p.281-312.

ATERRO sanitário. Disponível em:

< http://ec.europa.eu/environment/youth/waste/waste landfill pt.html > . Acesso em 14 dez. 2010.

BETTIOL, W.; CAMARGO, O.A. Impacto ambiental do uso agrícola do lodo de esgoto. Jaguariúna: Embrapa Meio Ambiente, 2000. 312p.

CONDER. Destinação final adequada do lixo urbano para municípios de pequeno porte. Disponível em: < http://www.conder.ba.gov.br/macarani.htm> Acesso em 14 dez. 2010.

FRANK, R. The use of biosolids from wastewater treatment plants in agriculture. Enviromental Management, New York, v.9, n. 4, p. 165-169, Apr. 1998.

GALDOS, M.V.; MARIA, I.C. de; CAMARGO, O. A. Atributos químicos e produção de milho em um Latossolo Vermelho eutroférrico tratado com lodo de esgoto. Revista Brasileira de Ciência do Solo, v.28, p.569-577, 2004.

GOBBI, M. A. Potencialidade do uso do lodo de esgoto como fonte de macronutrientes no cultivo do milho (Zea mays L.) no município de Maringá - PR. 2003. Tese (Doutorado em Agronomia/Energia na Agricultura) - Faculdade de Ciências Agronômicas. Universidade Estadual Paulista. Botucatu.

GUEDES, M. C.; et al. Propriedades químicas do solo e nutrição do eucalipto em função da aplicação de lodo de esgoto. R. Bras. Ci. Solo, v.30, p.267-280, 2006.

HOFFMAN, R.et al. Administração da empresa agrícola. São Paulo: Pioneira, 1987. 325p.

MALTA, T. S. Aplicação de lodos de estações de tratamento de esgotos na agricultura: estudo do caso do município de Rio das Ostras - RJ. 2001. Dissertação (Mestrado) Fundação Oswaldo Cruz. Escola Nacional de Saúde Pública. Rio de Janeiro.

MELO, V. P. de. Propriedades químicas e disponibilidade de metais pesados para a cultura do milho em dois latossolos que receberam a adição de biossólido. 2002.

Dissertação (Mestrado em Agronomia/Produção Vegetal) - Faculdade de Ciências Agrárias e Veterinárias. Universidade Estadual Paulista. Jaboticabal.

NASCIMENTO, C.W.A.et al. Alterações químicas em solos e crescimento de milho e feijoeiro após aplicação de lodo de esgoto.Revista Brasileira de Ciência do Solo, v.28, p.385-392, 2004.

QUINTANA, N.R.G.et al. Características agronômicas de couve brócolos de cabeça única (Brassica oleraceae var. italica, híbrido decathlon) cultivado sob diferentes compostos contendo biossólido In: SIMPÓSIO SOBRE COMPOSTAGEM CIÊNCIA E TECNOLOGIA, 1, 2004, Botucatu. Anais... Faculdade de Ciências Agronômicas/UNESP, 2004. CD-Rom. 
QUINTANA, N. R. G. Análise econômica da aplicação de biossólido na agricultura. 2006.Dissertação (Mestrado em Agronomia/Energia na Agricultura) - Faculdade de Ciências Agronômicas. Universidade Estadual Paulista. Botucatu.

QUINTANA, N.R.G., CARMO, M. S. do, MELO, W.J.de. Viabilidade econômica do uso de lodo de esgoto na agricultura, Estado de São Paulo. R. Informações Econômicas, São Paulo, v.39, n.6, p.31-36, jun. 2009.

RAIJ, B. van. Uso agrícola de biossólidos. In: SEMINÁRIO SOBRE GERENCIAMENTO DE BIOSSÖLIDOS NO MERCOSUL, 1., 1998, Curitiba. Anais... Curitiba: SANEPAr; ABES, 1998. p.147-151.

ROCHA, G. N.; GONÇALVES, J.L.M.; MOURA, I.M. Mudanças da fertilidade do solo e crescimento de um povoamento de Eucalyptus grandis fertilizado com biosólido. Revista Brasileira de Ciência do Solo, v.28, p.623-639, 2004.

SABBEY, B.R. The use of sewage sludge as a fertilizer. London, 1974. p. 108-112. (Environmental Engineering Series, 72).

SILVA, J.E.; RESCK, D.V.S.; SHARMA, R.D. Alternativa agronômica para o biossólido produzido no Distrito Federal: I. Efeito na produção de milho e na adição de metais pesados em latossolo no Cerrado. Revista Brasileira de Ciência do Solo, v.26, p.487-495, 2002a. SILVA, J.E.; RESCK, D.V.S.; SHARMA, R.D. Alternativa agronômica para o biossólido produzido no distrito federal. II - Aspectos qualitativos, econômicos e práticos de seu uso. Revista Brasileira de Ciência do Solo, v.26, p.497-503, 2002 b.

SOUZA, W. J. O. Fósforo em solo tratado com biossólido e cultivado com milho. 2004. Tese (Doutorado em Agronomia/Produção Vegetal) - Faculdade de Ciências Agrárias e Veterinárias. Universidade Estadual Paulista. Jaboticabal.

TRANNIN I. C. B. Avaliação agronômica de um biossólido industrial e de seus efeitos sobre atributos do solo. 2004. Tese (Doutorado em Agronomia/ Solos e Nutrição de Plantas). Universidade Federal de Lavras.

TRANNIN, I. C. B; SIQUEIRA, J.O.; MOREIRA, F.M.S. Avaliação agronômica de um biossólido industrial para a cultura do milho. Pesquisa Agropecuária Brasileira, Brasília, v.40, n.3, p.261-269, mar. 2005.

TRIGUEIRO, R. M. Uso de biossólidos como substrato para produção de mudas de pinus e eucalipto. 2002. Dissertação (Mestrado em Agronomia/Energia na Agricultura) - Faculdade de Ciências Agronômicas. Universidade Estadual Paulista. Botucatu.

TSUTIYA, M. T. Alternativas de disposição final de biossólidos gerados em estações de tratamento de esgoto. In: BETTIOL, W.; CAMARGO, O.A. (Ed.). Impacto ambiental do uso agrícola do lodo de esgoto. Jaguariúna: Embrapa Meio Ambiente, 2000. p.69-105.

TSUTIYA, M. T. Alternativas de disposição final de biossólidos. In: TSUTIYA, M.T.et al. (Ed.). Biossólidos na Agricultura. São Paulo: SABESP, 2001. p.133-180. 
